\title{
Adherence to Continuous Positive Airway Pressure Therapy for Obstructive Sleep Apnea: Impact of Patient Education after a Longer Treatment Period
}

\author{
Florian S. Fuchs ${ }^{a}$ Adriano Pittarelli ${ }^{a}$ Eckhart G. Hahn ${ }^{a}$ Joachim H. Ficker ${ }^{b}$ \\ ${ }^{a}$ Medical Department 1, Friedrich Alexander University of Erlangen-Nuremberg, Erlangen, and \\ ${ }^{b}$ Medical Department 3 (Respiratory Medicine, Allergology and Sleep Medicine), Klinikum Nuremberg, \\ Nuremberg, Germany
}

\section{Key Words}

Continuous positive airway pressure $\cdot$ Obstructive sleep apnea syndrome - Patient education · Treatment adherence

\begin{abstract}
Background: Continuous positive airway pressure (CPAP) is the standard treatment for obstructive sleep apnea (OSA) but it is often cumbersome so that adherence to CPAP therapy is limited. Objectives: We evaluated adherence to CPAP therapy after an additional educative intervention in OSA patients after a longer treatment period. Methods: A short patient information program covering many aspects of symptoms, consequences and treatment of OSA was created, and standardized information sessions were developed to be given by an experienced sleep physician to $>6,000$ participants of patient support group meetings throughout Germany. They also received a booklet containing the essential information of the lectures. Of the 526 randomly selected members of these support groups receiving the anonymized questionnaire by mail, 475 CPAP patients sent the questionnaire back. Of these CPAP patients, 243 participated in a lecture und and had received a booklet (information group) and 232 CPAP patients had not attended a lecture (control
\end{abstract}

group). Results: In the information group, a significantly higher daily usage of CPAP devices (6.9 $\pm 0.9 \mathrm{~h} /$ day) was reported compared with the control group $(5.7 \pm 1.3 \mathrm{~h} / \mathrm{day}$; $p<0.001)$. Furthermore, the score in the Epworth Sleepiness Scale (ESS) was found to be significantly lower in the information group (median $\mathrm{ESS}=6$, interquartile range, IQR, 4-8 vs. median $=11$, IQR $8-13 ; p<0.001)$. Conclusions: Patients who attended our short information program showed a higher daily usage and a lower subjective daytime sleepiness. These results suggest that patients on CPAP therapy may benefit from education even after a longer treatment period.

Copyright $\odot 2009$ S. Karger AG, Basel

\section{Introduction}

The obstructive sleep apnea (OSA) syndrome is increasingly being recognized as a disorder associated with an increased risk for cardiovascular diseases [1] and adverse effects on quality of life mainly by excessive daytime sleepiness, depression and impairments in both mental and physical performance [2]. The prevalence of OSA is estimated to be at least $4 \%$ in men and $2 \%$ in women [3]. The standard treatment of OSA is continuous pos- 
Table 1. Topics of the lectures

Basic information about sleep-related breathing disorders (snoring/sleep apnea)

Physiology of sleep and breathing during sleep

Pictures of typical patterns of disturbed breathing during sleep

Signs and symptoms of sleep-related breathing disorders

Impact of sleep-related breathing disorders on quality of life

Long-term complications of sleep-related breathing disorders

Diagnostic/therapeutic approach to sleep-related breathing disorders

itive airway pressure (CPAP), first described by Sullivan et al. [4] in 1981. CPAP has been demonstrated to improve daytime performance and reduce cardiovascular effects associated with OSA $[5,6]$.

To reach those beneficial effects, patients should use their CPAP devices regularly. CPAP adherence in patients with obstructive sleep apnea has been intensively studied [7-14]. The main endpoint of most studies was CPAP usage time per night. Up to now, it is still unclear how long CPAP therapy should be applied to be successful. The effect of CPAP therapy might be dose dependent $[8,15]$. Usage of the CPAP device for at least $4 \mathrm{~h}$ per night and $>70 \%$ of the nights is discussed to be a reasonable threshold for good adherence $[12,16]$. Various factors associated with good adherence could be identified, including female gender, increasing age, reduction of daytime sleepiness by CPAP [8] and severity of OSA $[7,17]$.

One important way to improve adherence is patient education [18-22]; patient education is therefore recommended in all patients receiving CPAP therapy for OSA [23]. Most previous studies focused on the effect of patient education before, during or shortly after the initiation of CPAP therapy. To date, there are hardly any data on the effect of educational interventions in patients on long-term CPAP treatment. Thus, the aim of this study was to investigate the effect of an educative intervention presented as a short comprehensive patient information program applied after a longer period of CPAP therapy on adherence and subjective daytime sleepiness in patients with OSA.

\section{Patients and Methods}

\section{Patient Information Program}

A patient information program was developed consisting of a standardized 120-min lecture emphasizing the cardiovascular and psychosocial impacts of snoring and OSA as well as beneficial effects of CPAP therapy. Proper handling of CPAP devices, masks, humidifiers and other accessories was taught and various methods to reduce side effects of CPAP were demonstrated together with a variety of practical 'tips and tricks'. Pros and cons of alternative therapies were discussed.

Patient self-support groups throughout Germany were contacted and these lectures were given during their meetings. Each of the meetings involved about $20-80$ patients. Usually, all members of a support group were invited to the lecture. Before study commencement, the patients' feedback to the lectures had been used to continuously improve the information program. During the study period, all lectures were given in a nearly identical way by one experienced sleep physician (A.P.). An interactive presentation style was practiced using Microsoft ${ }^{\circledR}$ PowerPoint ${ }^{\circledR}$ presentations with instructive graphics and pictures together with video sequences. At the end of the lectures, the patients were given the opportunity to address their personal problems with CPAP therapy. For reinforcement and information, a booklet was given to the participants, summarizing all topics of the lecture together with a glossary. The topics of the lectures are shown in table 1 .

124 such lectures were given to $>6,000$ participants throughout Germany. It was not checked if all participants were members of the respective support group. The study protocol was approved by the local ethics committee.

\section{Evaluation of the Information Program}

Support groups receiving the above-described standardized training lecture were asked to provide member lists including all members who are active at the time the lecture was done, i.e. members joining the support group meetings regularly $(5,264$ CPAP patients). Ten percent of all persons on each member list (526 CPAP patients) were randomly selected.

These self-support group members received an anonymized questionnaire by mail at least 90 days after each lecture asking for data on biometrics and CPAP usage (total time on CPAP therapy, number of days used/week and number of hours/night). In addition, the patients were asked about their self-assessment of their information status regarding sleep apnea and its therapy. For this question, a visual analogue scale ranging from 1 (very good information status) to 10 (no information) was used. Patients were also asked about their apnea-hypopnea index at the time of diagnosis, if known. Moreover, all 526 patients received a German version of the Epworth Sleepiness Scale (ESS) [24] for evaluation of their subjective daytime sleepiness. Moreover, they were asked whether they had attended the lectures and had received the information booklet or not to classify the study population as information or control group. Finally, the patients who attended the lectures were pleased to provide information on the period between the lecture and completion of the questionnaire.

\section{Data Collection and Statistical Analysis}

Metric data are presented as means \pm SD. Ordinal data are expressed as medians and interquartile ranges (IQR). The mean CPAP usage per day (in hours) was calculated using the formula: mean usage $(\mathrm{h} /$ day $)=$ total usage $(\mathrm{h} /$ week $) / 7$.

Comparisons between groups with mean values and normally distributed data were performed using Student's test for independent variables. To compare median values and non-normally distributed data, we used the Mann-Whitney U test. The comparison of percentages between groups was done using the $\chi^{2}$ test. 
Table 2. Biometric and treatment period data as reported in the questionnaire

\begin{tabular}{lccr}
\hline & $\begin{array}{l}\text { Control group } \\
(\mathrm{n}=232)\end{array}$ & $\begin{array}{l}\text { Information group } \\
(\mathrm{n}=243)\end{array}$ & $\begin{array}{l}\mathrm{p} \\
\text { value }\end{array}$ \\
\hline BMI & $32.0 \pm 4.7(20.7-45.4)$ & $32.3 \pm 4.8(22.5-48.8)$ & 0.664 \\
Age, years & $59.7 \pm 9.5(35-81)$ & $59.3 \pm 9.8(33-82)$ & 0.844 \\
Sex & & & \\
$\quad$ Male & $170(73.3 \%)$ & $192(79.0 \%)$ & \\
Female & $62(26.7 \%)$ & $51(21.0 \%)$ & 0.153 \\
Time on CPAP, months & $51.1 \pm 32.2(2-191)$ & $54.9 \pm 28.6(5-133)$ & $<0.001$ \\
ESS score & $11(8-13)$ & $6(4-8)$ & \\
\hline
\end{tabular}

There were no significant differences between both groups.

Means \pm SD and medians (IQR) are presented.
For differences between groups, we considered a two-tailed $\mathrm{p}<$ 0.05 to be significant. Pearson's test or Spearman's test was applied to calculate correlation coefficients, as appropriate.

All statistical analyses were performed using SPSS (version 15.0; SPSS, Chicago, Ill., USA).

\section{Results}

Of the 526 mailed questionnaires, 475 were returned and analyzed (90.3\%). Of these 475 patients, 243 belonged to the information group and 232 to the control group. The basic characteristics of the information and control groups are shown in table 2 .

There were no significant differences in age, body mass index and gender between both patient groups. The treatment period (time between initiation of CPAP therapy and questionnaire evaluation) did also not significantly differ between both groups. The mean latency between the standardized training lecture and the evaluation of the questionnaires was $226 \pm 108$ days, with no significant difference between both groups. Patients of the information group rated their information status significantly higher $($ median $=1 ; \mathrm{IQR}=1-2$ vs. median $=9$; IQR = 6-9; p < 0.001).

One hundred and forty patients in the control group and 148 patients in the information group reported an apnea-hypopnea index at the time of diagnosis (27.5 \pm 20.7 vs. $29.4 \pm 21.4$; nonsignificant).

\section{Daily CPAP Usage}

Patients who had participated in the information program reported a significantly higher mean daily usage than the control group $(6.9 \pm 0.9$ vs. $5.7 \pm 1.3 \mathrm{~h} /$ day; $\mathrm{p}<$ 0.001 ; table 3). The scatter plot showed a tendency towards higher daily usage with increasing time on CPAP

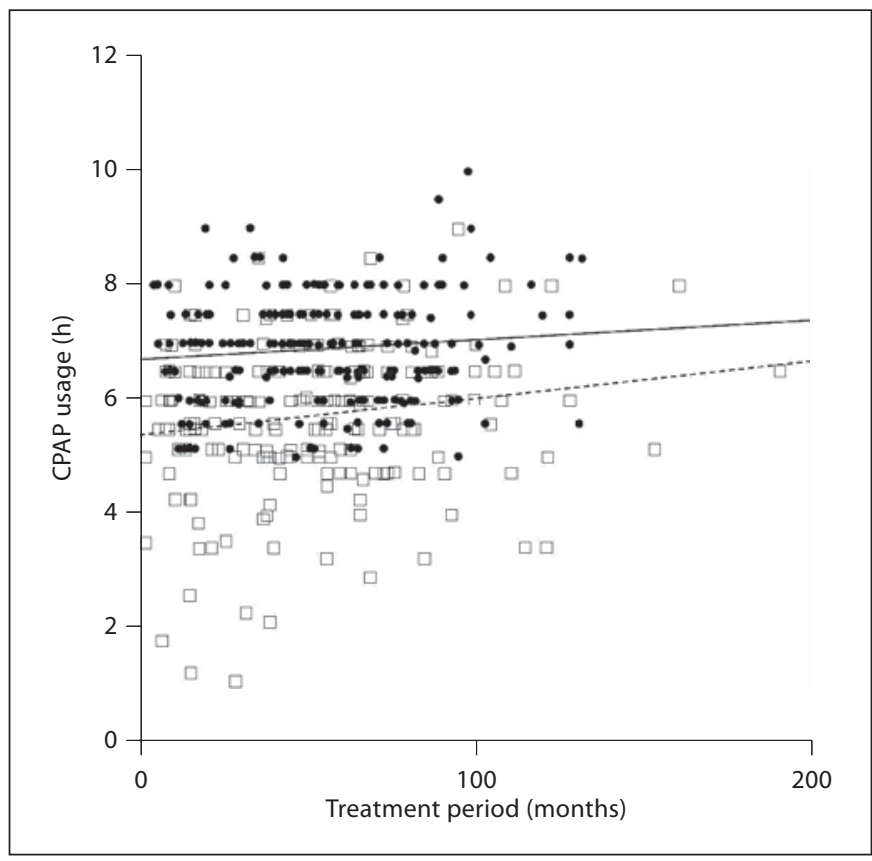

Fig. 1. Correlation of treatment period (months) and daily CPAP usage (h). $\square /---=$ Information group; $\bullet /-=$ control group.

therapy (fig. 1). Dividing the study population into two groups, using the median (group 1 with usage period $<52.5$ months and group 2 with $\geq 52.5$ months), showed that patients using their CPAP device for $\geq 52.5$ months had a significantly higher daily usage in the total study population ( $6.5 \pm 1.2$ vs. $6.2 \pm 1.3 \mathrm{~h}$ /day; $\mathrm{p}=0.038)$. In the control group, we found a significantly higher daily usage in those patients with longer time on CPAP therapy $(5.9 \pm 1.2$ vs. $5.5 \pm 1.4 \mathrm{~h} /$ day; $\mathrm{p}=0.025)$ whereas the information group did not show that dependency $(6.9 \pm 1$ vs. $6.9 \pm 0.9 \mathrm{~h} /$ day; nonsignificant). 
Table 3. Daily CPAP usage (h/day) depending on gender, treatment period and age as reported in the questionnaire

\begin{tabular}{|c|c|c|c|}
\hline & Total & $\begin{array}{l}\text { Control } \\
\text { group }\end{array}$ & $\begin{array}{l}\text { Information } \\
\text { group }\end{array}$ \\
\hline All patients & $6.3 \pm 1.3$ & $5.7 \pm 1.3$ & $6.9 \pm 0.9$ \\
\hline \multicolumn{4}{|l|}{ Gender } \\
\hline Male & $6.3 \pm 1.3$ & $5.6 \pm 1.2$ & $6.9 \pm 0.9$ \\
\hline Female & $6.5 \pm 1.3$ & $5.9 \pm 1.3$ & $7.1 \pm 0.9$ \\
\hline $\mathrm{p}$ value & NS & NS & NS \\
\hline \multicolumn{4}{|l|}{ Treatment period } \\
\hline$<52.5$ months & $6.2 \pm 1.3$ & $5.5 \pm 1.4$ & $6.9 \pm 0.9$ \\
\hline$\geq 52.5$ months & $6.5 \pm 1.2$ & $5.9 \pm 1.2$ & $6.9 \pm 1.0$ \\
\hline $\mathrm{p}$ value & 0.038 & 0.025 & NS \\
\hline \multicolumn{4}{|l|}{ Age } \\
\hline$<60$ years & $6.2 \pm 1.1$ & $5.6 \pm 1.1$ & $6.7 \pm 0.9$ \\
\hline$\geq 60$ years & $6.5 \pm 1.4$ & $5.8 \pm 1.4$ & $7.2 \pm 0.9$ \\
\hline $\mathrm{p}$ value & 0.001 & NS & $<0.001$ \\
\hline
\end{tabular}

All differences between the control and information group were highly significant $(\mathrm{p}<0.001)$.

$\mathrm{NS}=$ Nonsignificant. Means $\pm \mathrm{SD}$.

There was no gender-related difference in daily CPAP usage. In the total study population and in the information group, daily CPAP usage was significantly higher in patients aged $\geq 60$ years but not in the control group.

\section{Daytime Sleepiness}

The median ESS score in the information group (median $=6$, IQR 4-8) was significantly lower than in the control group (median $=11$, IQR 8-13; $\mathrm{p}<0.001$ ).

There was a negative correlation of the ESS score with daily CPAP usage $(r=-0.33, p<0.001)$, indicating that patients with longer daily CPAP usage tended to report less daytime sleepiness. When the study population was divided according to the median value of daily CPAP usage into one group with a daily usage $<6.5 \mathrm{~h} /$ day $(\mathrm{n}=228)$ and another with $\geq 6.5 \mathrm{~h} /$ day $(\mathrm{n}=249)$, patients using their CPAP device $<6.5 \mathrm{~h}$ /day showed a significantly higher ESS score $($ median $=10$; IQR: $7-13$ vs. median $=7$; IQR: 4-10; $\mathrm{p}<0.001)$.

\section{Discussion}

Some data suggest that patient information might improve CPAP adherence [18-23] in OSA. Most previous studies focused on patient information prior or during the initiation of CPAP therapy $[18,25,26]$ but not after a longer treatment period. In the present study, we evaluated the impact of a comprehensive patient information program for CPAP patients after a longer treatment period.

In our study, the patients who had reported attendance at the information program were found to have a significantly higher daily usage of the CPAP device and significantly lower subjective daytime sleepiness established by the ESS compared with the control group. On the one hand, regular attendance at support group meetings could indicate increased motivation which is associated with better CPAP adherence. On the other hand, possibly patients encountering problems with CPAP treatment and consequently adhering less to CPAP therapy are less reluctant to contact a support group. Since all patients were recruited from support group member lists, these aspects should not bias our study, but the results cannot easily be conferred to patients who are not members of support groups.

We did not ask for CPAP devices, pressure mode (e.g. conventional vs. auto-CPAP) or way of pressure delivery (e.g. nasal vs. full face mask). Thus, the effect of the therapy system on our results was not determined and has to be taken into account in future studies. However, we do not expect any significant effect because patients from many different prescribers were investigated. Moreover, conventional CPAP is still the most frequently prescribed kind of CPAP therapy in Germany.

However, potential limitations of our study remain because we did not carry out a randomization; instead an allocation to the information/control group was done based on the patients' statement. Patients with poor therapy adherence who have attended our lectures but did not change their adherence thereafter may have stated that they did not attend, whereas patients who did not attend, although they knew that it took place, stated attendance because of a bad conscience or they feared negative consequences for example by their health insurance despite the anonymized survey. Both groups had a similar size and showed similar biometric data, and no significant differences in time on CPAP therapy. We decided to perform a comparison of both groups although other important confounders of CPAP adherence were not evaluated by our questionnaire. Especially daytime sleepiness in untreated OSA, initial response to CPAP therapy and quality of patient education prior or during therapy initiation might be significant confounders. Reduction of daytime sleepiness by CPAP [8] and severity of OSA [7, 17] were associated with good adherence. Maybe patients in the information group a priori had higher adherence 
because of the above-mentioned factors. Furthermore, patients with a good early therapy success are possibly more motivated to keep the quality of therapy at a high standard and utilize offers like our lecture more often than patients with less successful therapy.

We did not perform sample size calculation for lack of results of comparable interventions, and therefore we could not estimate any expectable difference. For the purpose of our study, inclusion of approximately $500 \mathrm{pa}-$ tients seemed to suffice. Most other studies investigated $<100$ patients. Consequently, we sent the questionnaire to $10 \%$ of all active members on the member lists, which resulted in a study cohort of 526 patients. For sample size calculation of a randomized controlled trial, the expectable effect should be assumed less because of the abovementioned limitations.

Another major limitation of our study is the lack of pre-interventional data on CPAP usage. The differences in CPAP usage (6.9 vs. $5.7 \mathrm{~h} /$ day) were highly significant. However, we are not able to show improvement by our data. Possibly adherence and consequently day time sleepiness were already significant better in the information group prior to the lectures, but this seems not very probable in our opinion.

Our main endpoint is based on self-reported CPAP usage. The uncertain validity of the patients' statements might be considered to be a major limitation of our study, since previous studies comparing subjective and objective adherence in the same patients showed significant differences, with a tendency to overestimate the real usage time by the patients $[9,11]$. In our study, a mean CPAP usage of $5.7 \pm 1.3 \mathrm{~h}$ /day was reported in our control group together with a quite high ESS score of 11 (IQR $8-13)$, possibly indicating a tendency to overestimate CPAP usage also in our study. On the other hand, we compared self-reported CPAP adherence of both study groups. Thus, the subjective measures should actually be acceptable. However, patients in the control group could have stated a higher daily usage because they missed the lecture resulting in a bad conscience when receiving the questionnaire. Therefore, the real difference between both groups would have been higher. On the other hand, CPAP patients who attended the lectures could overestimate their daily usage because of fear for consequences of low adherence leading to a less or even nonexisting difference between both groups in reality.

The results of this study correlate with the results of Russo-Magno et al. [27], for example; in their study, 20 of 33 study patients used their CPAP device $5 \mathrm{~h} /$ night or longer (therefore being defined as compliant). It appeared that $95 \%$ of these patients belonged to a support group and had received an information program. Three further studies $[8,17,18]$ indicated beneficial effects of education programs but failed to provide data showing to what extent adherence was improved by the information programs since no control groups were studied. In contrast to our study, most education programs had been applied prior or during the initiation of CPAP therapy in the sleep laboratory $[8,16,18,21,25,26]$. We performed patient education partially several years after therapy initiation and could show improvement of adherence even after a long treatment period.

Subjective daytime sleepiness established by the ESS was significantly lower in our information group than in our control group. In contrast, Hoy et al. [18] did not find differences in subjective daytime sleepiness in their patients, who had been randomized to a standard or an intensive information group. However, the standard group had received comprehensive information together with practical training during the initiation of CPAP therapy and thus might have been better educated than our control group.

In our patients, good CPAP adherence was associated with a lower ESS score. This finding supports the hypothesis that improving CPAP adherence may increase beneficial effects of CPAP therapy. However, some authors interpret such data with caution and hypothesized that patients might underestimate the severity of their symptoms as soon as they are treated [28]. We cannot rebut such arguments for lack of objective data on daytime symptoms.

Our study points out that even when longer periods of time have passed after initiation of CPAP therapy adherence can possibly be improved by well-designed information programs. However, intensive patient education in the sleep laboratory during the initiation phase of treatment is mandatory and additional information programs at a later time cannot serve as a substitute, since longterm adherence to CPAP therapy is largely determined by the initial treatment period [17].

It could be of interest to study the efficiency of less comprehensive information programs. Enforcement by telephone alone has not been demonstrated to be sufficient [29]. Chervin et al. [21] found a more considerable effect on improving adherence by brochures than by regular phone calls. So we decided not only to perform a standardized lecture but also to hand out a booklet to the participants. It remains to be seen which elements of information programs are most effective. For the next generation of CPAP patients, web-based information distri- 
bution may play an important role although the design of educational interventions has to be balanced against the costs. Further research should be carried out to analyze the effect of regular repeated information on OSA patients taking economical aspects for the patient and the health care system into account.

In summary, our data showed higher CPAP adherence and less daytime sleepiness in patients who attended a short comprehensive information program after a longer treatment period consisting of a lecture and a booklet. Due to the above-mentioned limitations of the study, we were not able to prove that this was an effect of our intervention. The effect of repeated education of OSA patients has to be validated in a prospective randomized controlled trial. Our results suggest that this may be an important intervention to improve adherence.

\section{References}

-1 McNicholas WT, Bonsigore MR: Sleep apnoea as an independent risk factor for cardiovascular disease: current evidence, basic mechanisms and research priorities. Eur Respir J 2007;29:156-178.

$\checkmark 2$ Flemons WW, Tsai W: Quality of life consequences of sleep-disordered breathing. J Allergy Clin Immunol 1997;99:S750-S756.

-3 Young T, Palta M, Dempsey J, Skatrud J, Weber S, Badr S: The occurrence of sleep-disordered breathing among middle-aged adults. N Engl J Med 1993;328:1230-1235.

-4 Sullivan CE, Issa FG, Berthon-Jones M, Eves L: Reversal of obstructive sleep apnoea by continuous positive airway pressure applied through the nares. Lancet 1981;i:862-865.

5 Giles TL, Lasserson TJ, Smith BH, White J, Wright J, Cates CJ: Continuous positive airway pressure for obstructive sleep apnoea in adults. Cochrane Database Syst Rev 2006;3: CD001106.

6 Gordon P, Sanders MH: Sleep.7: positive airway pressure therapy for obstructive sleep apnoea/hypopnoea syndrome. Thorax 2005; 60:68-75

$>7$ Krieger J, Kurtz D, Petiau C, Sforza E, Trautmann D: Long-term compliance with CPAP therapy in obstructive sleep apnea patients and in snorers. Sleep 1996;19:136-143.

$>8$ Sin DD, Mayers I, Man GC, Pawluk L: Longterm compliance rates to continuous positive airway pressure in obstructive sleep apnea: a population-based study. Chest 2002; 121:430-435.

$>9$ Rauscher H, Formanek D, Popp W, Zwick H: Self-reported vs. measured compliance with nasal CPAP for obstructive sleep apnea. Chest 1993;103:1675-1680.

- 10 Engleman HM, Martin SE, Douglas NJ: Compliance with CPAP therapy in patients with the sleep apnoea/hypopnoea syndrome. Thorax 1994;49:263-266.

-11 Reeves-Hoche MK, Meck R, Zwillich CW: Nasal CPAP: an objective evaluation of patient compliance. Am J Respir Crit Care Med 1994;149:149-154.
2 Pepin JL, Krieger J, Rodenstein D, Cornette A, Sforza E, Delguste P, Deschaux C, Grillier V, Levy P: Effective compliance during the first 3 months of continuous positive airway pressure. A European prospective study of 121 patients. Am J Respir Crit Care Med 1999; 160:1124-1129.

$>13$ Meurice JC, Dore P, Paquereau J, Neau JP, Ingrand $\mathrm{P}$, Chavagnat JJ, Patte F: Predictive factors of long-term compliance with nasal continuous positive airway pressure treatment in sleep apnea syndrome. Chest 1994; 105:429-433.

14 Richard W, Venker J, den Herder C, Kox D, van den Berg B, Laman M, van Tinteren $H$, de Vries N: Acceptance and long-term compliance of nCPAP in obstructive sleep apnea. Eur Arch Otorhinolaryngol 2007;264:10811086.

15 Stepnowsky CJ, Dimsdale JE: Dose-response relationship between CPAP compliance and measures of sleep apnea severity. Sleep Med 2002;3:329-334.

16 Kribbs NB, Pack AI, Kline LR, Smith PL, Schwartz AR, Schubert NM, Redline S, Henry JN, Getsy JE, Dinges DF: Objective measurement of patterns of nasal CPAP use by patients with obstructive sleep apnea. Am Rev Respir Dis 1993;147:887-895.

17 McArdle N, Devereux G, Heidarnejad H, Engleman HM, Mackay TW, Douglas NJ: Long-term use of CPAP therapy for sleep apnea/hypopnea syndrome. Am J Respir Crit Care Med 1999;159:1108-1114.

18 Hoy CJ, Vennelle M, Kingshott RN, Engleman HM, Douglas NJ: Can intensive support improve continuous positive airway pressure use in patients with the sleep apnea/hypopnea syndrome? Am J Respir Crit Care Med 1999;159:1096-1100.

$>19$ Hui DS, Chan JK, Choy DK, Ko FW, Li TS, Leung RC, Lai CK: Effects of augmented continuous positive airway pressure education and support on compliance and outcome in a Chinese population. Chest 2000; 117:1410-1416.
20 Palmer S, Selvaraj S, Dunn C, Osman LM, Cairns J, Franklin D, Hulks G, Godden DJ: Annual review of patients with sleep apnea/ hypopnea syndrome - a pragmatic randomised trial of nurse home visit versus consultant clinic review. Sleep Med 2004;5:6165.

21 Chervin RD, Theut S, Bassetti C, Aldrich MS: Compliance with nasal CPAP can be improved by simple interventions. Sleep 1997; 20:284-289.

22 Likar LL, Panciera TM, Erickson AD, Rounds S: Group education sessions and compliance with nasal CPAP therapy. Chest 1997;111:1273-1277.

23 Kushida CA, Littner MR, Hirshkowitz M, Morgenthaler TI, Alessi CA, Bailey D, Boehlecke B, Brown TM, Coleman J Jr, Friedman L, Kapen S, Kapur VK, Kramer M, LeeChiong T, Owens J, Pancer JP, Swick TJ, Wise MS: Practice parameters for the use of continuous and bilevel positive airway pressure devices to treat adult patients with sleep-related breathing disorders. Sleep 2006;29: 375-380.

24 Bloch KE, Schoch OD, Zhang JN, Russi EW: German version of the Epworth Sleepiness Scale. Respiration 1999;66:440-447.

25 Jean Wiese H, Boethel C, Phillips B, Wilson JF, Peters J, Viggiano T: CPAP compliance: video education may help! Sleep Med 2005;6: 171-174.

26 Richards D, Bartlett DJ, Wong K, Malouff J, Grunstein RR: Increased adherence to CPAP with a group cognitive behavioral treatment intervention: a randomized trial. Sleep 2007; 30:635-640.

27 Russo-Magno P, O’Brien A, Panciera T, Rounds S: Compliance with CPAP therapy in older men with obstructive sleep apnea. J Am Geriatr Soc 2001;49:1205-1211.

28 Krieger J, Kurtz D: Objective measurement of compliance with nasal CPAP treatment for obstructive sleep apnoea syndrome. Eur Respir J 1988;1:436-438.

29 Fletcher EC, Luckett RA: The effect of positive reinforcement on hourly compliance in nasal continuous positive airway pressure users with obstructive sleep apnea. Am Rev Respir Dis 1991;143:936-941. 